\title{
Clinically relevant concentrations of dexmedetomidine may reduce oxytocin-induced myometrium contractions in pregnant rats
}

\section{Dong Joon Kim ${ }^{1,2}$, Young Joon $\mathrm{Ki}^{2,3}$, Bo Hyun Jang ${ }^{2}$, Seongcheol Kim², Sang Hun Kim ${ }^{1,2}$, and Ki Tae Jung ${ }^{1,2}$}

'Department of Anesthesiology and Pain Medicine, College of Medicine, Chosun University, ${ }^{2}$ Department of Anesthesiology and Pain Medicine, Chosun University Hospital, ${ }^{3}$ Department of Medicine, Graduate School, Chosun University, Gwangju, Korea
Received May 14, 2020

Revised July 3, 2020

Accepted July 4, 2020

\section{Corresponding author}

Ki Tae Jung, M.D., Ph.D.

Department of Anesthesiology and

Pain Medicine, Chosun University

Hospital, 365 Pilmun-daero, Dong-gu,

Gwangju 61453, Korea

Tel: 82-62-220-3223

Fax: 82-62-223-2333

E-mail: mdmole@chosun.ac.kr
Background: Recently, there have been some trials to use dexmedetomidine in the obstetric field but concerns regarding the drug include changes in uterine contractions after labor. We aimed to evaluate the effects of dexmedetomidine on the myometrial contractions of pregnant rats.

Methods: In a pilot study, the contraction of the myometrial strips of pregnant Sprague-Dawley rats in an organ bath with oxytocin at $1 \mathrm{mU} / \mathrm{ml}$ was assessed by adding dexmedetomidine from $10^{-6}$ to $10^{-2} \mathrm{M}$ accumulatively every $20 \mathrm{~min}$, and active tension and the number of contractions were evaluated. Then, changes in myometrial contractions were evaluated from high doses of dexmedetomidine $\left(1.0 \times 10^{-4}\right.$ to $\left.1.2 \times 10^{-3} \mathrm{M}\right)$. The effective concentrations (EC) for changes in uterine contractions were calculated using a probit model.

Results: Active tension and the number of contractions were significantly decreased at $10^{-3}$ $\mathrm{M}$ and $10^{-4} \mathrm{M}$ dexmedetomidine, respectively $(\mathrm{P}<0.05)$. A complete loss of contractions was seen at $10^{-2} \mathrm{M}$. Dexmedetomidine $\left(1.0 \times 10^{-4}\right.$ to $\left.1.2 \times 10^{-3} \mathrm{M}\right)$ decreased active tension and the number of contractions in a concentration-dependent manner. The $\mathrm{EC}_{95}$ of dexmedetomidine for inhibiting active tension and the number of contractions was $5.16 \times 10^{-2}$ $\mathrm{M}$ and $2.55 \times 10^{-5} \mathrm{M}$, respectively.

Conclusions: Active tension of the myometrium showed a significant decrease at concentrations of dexmedetomidine higher than $10^{-3} \mathrm{M}$. Thus, clinical concentrations of dexmedetomidine may inhibit uterine contractions. Further research is needed for the safe use of dexmedetomidine in the obstetrics field.

Keywords: Adrenergic alpha-agonists; Alpha 2 adrenergic receptors; Dexmedetomidine; Rat; Relaxation; Smooth muscle; Uterine contraction; Uterus.

\section{INTRODUCTION}

Dexmedetomidine is a highly selective $\alpha_{2}$ adrenergic receptor (AR) agonist which has been in the spotlight be- cause of its analgesic properties and sedative effect without respiratory depression [1]. Recently, its clinical applications have been expanded beyond use in the intensive care unit and operating room. The additional properties of dex-

This is an Open Access article distributed under the terms of the Creative Commons Attribution Non-Commercial License (http://creativecommons.org/licenses/by-nc/4.0) which permits unrestricted non-commercial use, distribution, and reproduction in any medium, provided the original work is properly cited.

Copyright (C) the Korean Society of Anesthesiologists, 2020 
medetomidine, such as anxiolysis, reducing anesthetic requirement when used as an adjuvant, and cardiovascular stability, can be attractive factors when considering the use of dexmedetomidine in pregnant women [2]. Several trials of dexmedetomidine have been conducted in the obstetrics field, such as application as an adjuvant analgesic with remifentanil during labor [3], as an adjuvant during general anesthesia for cesarean sections in normal pregnancies [4], in a parturient with preeclampsia [5], or as the sole sedative during cesarean section under spinal anesthesia [6]. However, there are some concerns for the use of dexmedetomidine for obstetric anesthesia, such as changes in uterine contractions after labor and fetal effects by placental transfer [2]. Although some human and animal studies reported that dexmedetomidine increased spontaneous contractions of the myometrium [7-9], the studies used relatively low concentrations of dexmedetomidine in vitro, which seem insufficient in clinical use [10]. Also, there are some conflicting reports that clonidine, a non-selective $\alpha_{2}$ AR agonist, did not affect uterine contractions and that $\alpha_{2}$ AR does not participate in the contractile response of the myometrium [11].

In this study, we evaluated the effects of dexmedetomidine on oxytocin-induced contractions of the myometrium in pregnant rats. We also calculated the effective concentration for changes in the contractile profiles and compared them with the clinical concentration of dexmedetomidine used for sedation.

\section{MATERIALS AND METHODS}

\section{Animals}

After approval by the Animal Care and Use Committee (no. CIACUC2018-S0043), the current study was conducted following Animal Research: Reporting of In Vivo Experiments guidelines [12]. A total of 10 specific-pathogen-free Sprague-Dawley pregnant rats (weighing 200-250 g) were used for the study (pilot study, $\mathrm{n}=2$; concentration-response study, $n=8$ ). The rats were purchased from Damul Science (Korea) and brought to the laboratory on the 17th day of pregnancy. The pregnant rats were housed for one day in cages with free access to water and food located in a room maintained with a light/dark cycle of $12: 12$ and constant temperature $\left(20\right.$ to $\left.23^{\circ} \mathrm{C}\right)$.

\section{Tissue preparation}

The study was performed from 9:00 a.m. to 5:00 p.m. in the laboratory. The pregnant rats were euthanized by an infusion of carbon dioxide into the chamber on the 18th day of pregnancy, which is comparable to about 31-32 weeks of pregnancy in humans [13]. Immediately, the abdomen of the rat was incised, and the pregnant uterus was isolated. The uterus was transferred to a petri dish filled with Krebs solution (118.3 mM NaCl, $4.7 \mathrm{mM} \mathrm{KCl}, 2.5 \mathrm{mM}$ $\mathrm{CaCl}_{2}, 25 \mathrm{mM} \mathrm{NaHCO}, 1.2 \mathrm{mM} \mathrm{KH_{2 }} \mathrm{PO}_{4}, 1.2 \mathrm{mM} \mathrm{MgCl}_{2}$, and $11.1 \mathrm{mM}$ glucose) [14]. The dissected uterus was carefully trimmed of fat and connective tissue and cut in the longitudinal direction. Myometrial strips were prepared in approximately $5 \mathrm{~mm} \times 10 \mathrm{~mm}$ sections. Then, a myometrial strip was mounted in an organ bath, which was filled with Krebs solution. The bath consisted of double walls and had a capacity of $25 \mathrm{ml}$. Heated water was circulated in the space between the two walls of the bath to maintain a temperature of $37^{\circ} \mathrm{C}$. The end of the strip was anchored with a triangular clip and both ends were connected to a hook on the base of the organ bath and lever arm of a force-displacement transducer (Isometric Transducer; Harvard App Ltd., USA). The Krebs solution in the bath was maintained at a $\mathrm{pH}$ of approximately 7.4 by continuous aeration with a gas mixture of $95 \%$ oxygen and $5 \%$ carbon dioxide.

\section{Drug preparation}

Dexmedetomidine powder (purity $\geq 98 \%$, CAS Number 145108-58-3, $\mathrm{C}_{13} \mathrm{H}_{16} \mathrm{~N}_{2} \cdot \mathrm{HCl}$, molecular weight $236.74 \mathrm{~g} /$ mol) was purchased from Sigma-Aldrich (USA) and was prepared by dissolving in distilled water $(20 \mathrm{mg} / \mathrm{ml})$. Then, the dexmedetomidine solution was diluted to varying concentrations for the concentration-response study; $10^{-6}$ to $10^{-2} \mathrm{M}$ for the pilot study, and $1.0 \times 10^{-4}$ to $1.2 \times 10^{-3} \mathrm{M}$ for the concentration-response study.

\section{Measurement of isometric tension}

After the myometrial strips were mounted, the isometric tension of the strips was assessed using a force-displacement transducer. The default value for isometric tension was determined using a $2.0 \mathrm{~g}$ weight and an initial resting tension of $2.0 \mathrm{~g}$ was applied to the myometrial strips for 60 min for equilibration by flushing fresh Krebs solution in 
the organ bath every $20 \mathrm{~min}$. During the equilibration, rhythmic spontaneous contractions of the myometrial strips developed, and $1 \mathrm{mU} / \mathrm{ml}$ of oxytocin (Sigma-Aldrich) was added to the organ bath [9]. During the equilibration with oxytocin for a further $60 \mathrm{~min}$, the myometrial strips developed strong, regular contractions. Then, the isometric tension was measured over the $20 \mathrm{~min}$ and used as control values. The measured data were traced with an i-WORX 118 system (USA) and recorded by Labscribe software (Windows ver. 2.0; iWorx Systems Inc.).

\section{Quantitative measurement of changes in myometrial strip contractions}

Changes in myometrial strip contractions during the time interval were calculated by data quantitatively measured by the force-displacement transducer. Active tension was calculated as the difference between the peak tension and the resting tension during contractions of the myometrial strip. The number of contractions was expressed as the number of contractions for 20 min of each concentration of dexmedetomidine.

\section{Pilot study}

To evaluate the concentration-response of dexmedetomidine on pregnant myometrial strips and determine concentrations for the probit analysis, a pilot study was conducted $(\mathrm{n}=2)$. Dexmedetomidine concentrations from $10^{-6}$ to $10^{-2} \mathrm{M}$ were added to the organ bath accumulatively. Changes in the contractions of the myometrial strip at each concentration of dexmedetomidine were observed.

\section{Concentration-response study}

According to the results of a pilot study, the concentrations used to evaluate the concentration-response curve by probit analysis were: $1.0 \times 10^{-4} \mathrm{M}, 3.0 \times 10^{-4} \mathrm{M}, 6.0 \times 10^{-4}$ $\mathrm{M}, 9.0 \times 10^{-4} \mathrm{M}$, and $1.2 \times 10^{-3} \mathrm{M}$. In the pilot study, varying concentrations of dexmedetomidine were added accumulatively to the organ bath every $20 \mathrm{~min}$ and changes in contractions of the myometrial strip were observed $(n=8)$.

\section{Statistical analysis}

The data are expressed as mean \pm standard deviation. The effects of dexmedetomidine at each concentration were compared to the control data, and changes in active tension and number of contractions were described as a percentage. Shapiro-Wilk tests were used to analyze the normality of distribution of the data, and one-way analysis of variance or the Kruskal-Wallis test using SPSS (Windows ver. 21.0, IBM Co., USA) were performed for comparisons with the control. A post-hoc test was followed by MannWhitney $U$ test with Scheffes's method. A P value of less than 0.05 was considered statistically significant. Probit analysis was performed to analyze the effective concentration (EC) of dexmedetomidine on the changes in active tension and the number of contractions of the myometrial strips [15]. The calculated EC data are described as concentrations and $95 \%$ confidence intervals (CI) according to the percentage of change as $\mathrm{EC}_{5}$ ( $\mathrm{EC}$ for the $5 \%$ change), $\mathrm{EC}_{25}, \mathrm{EC}_{50}, \mathrm{EC}_{75}$, and $\mathrm{EC}_{95}$.

\section{RESULTS}

\section{Pilot study}

No significant effect on myometrial contractions was induced by oxytocin in dexmedetomidine concentrations from $10^{-6}$ to $10^{-5} \mathrm{M}$ (Fig. 1). However, higher concentrations of dexmedetomidine decreased the active tension and number of contractions. The active tension and number of

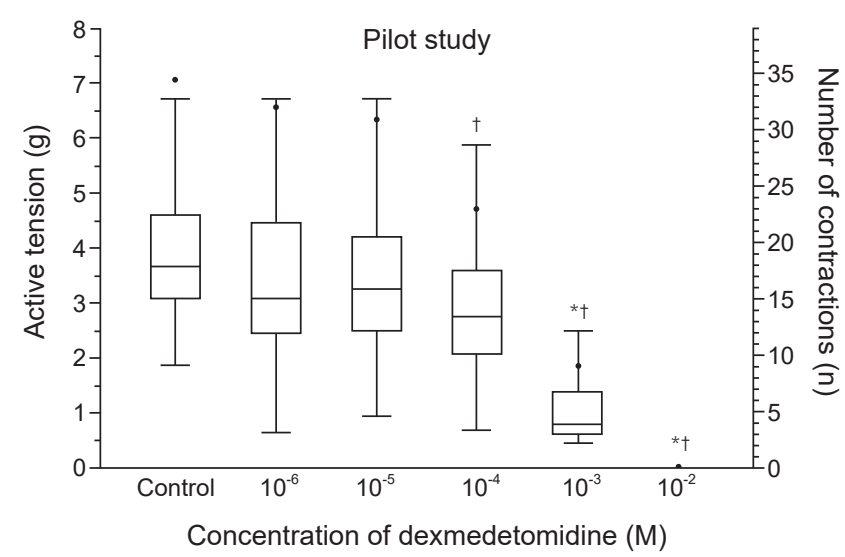

Fig. 1. A pilot study on the changes in myometrial contractions caused by dexmedetomidine. There was no significant effect of dexmedetomidine concentrations from $10^{-6}$ to $10^{-5} \mathrm{M}$ on myometrial contractions. Active tension and the number of contractions were significantly decreased by dexmedetomidine concentrations of $10^{-3}$ $\mathrm{M}$ and $10^{-4} \mathrm{M}$, respectively. Both active tension and the number of contractions disappeared at $10^{-2} \mathrm{M}$. The box plot represents active tension. Data are expressed as median (1Q, 3Q). The black dots represent the number of contractions. Data are expressed as mean. ${ }^{*} p<0.05$ compared to the control active tension. ${ }^{\dagger} p<0.05$ compared to the control number of contractions. 
contractions were significantly decreased from dexmedetomidine concentrations of $10^{-3} \mathrm{M}$ and $10^{-4} \mathrm{M}$, respectively $(\mathrm{P}<0.05)$. Complete relaxation and a loss of myometrial strip contractions were found at $10^{-2} \mathrm{M}$ dexmedetomidine.

\section{Concentration-response study}

As the concentration of the dexmedetomidine increased $\left(1.0 \times 10^{-4}\right.$ to $\left.1.2 \times 10^{-3} \mathrm{M}\right)$, the active tension and number of contractions decreased in a concentration-dependent manner (Table 1). Both active tension and the number of contractions were significantly decreased by $1.0 \times 10^{-4} \mathrm{M}$ dexmedetomidine $(\mathrm{P}<0.05)$.

The $\mathrm{EC}_{50}$ and $\mathrm{EC}_{95}$ of dexmedetomidine to inhibit the active tension of the myometrial strip were $4.88 \times 10^{-5} \mathrm{M}(95 \%$ CI $\left.\left[2.29 \times 10^{-5} \mathrm{M}, 1.39 \times 10^{-4} \mathrm{M}\right]\right)$ and $5.16 \times 10^{-2} \mathrm{M}(95 \% \mathrm{CI}$ $\left[5.67 \times 10^{-3} \mathrm{M}, 5.28 \times 10^{0} \mathrm{M}\right]$ ), respectively (Table 2, Fig. 2). The $\mathrm{EC}_{50}$ and $\mathrm{EC}_{95}$ of dexmedetomidine to inhibit the number of myometrial strip contractions were $2.55 \times 10^{-5} \mathrm{M}(95 \%$ CI $\left.\left[1.41 \times 10^{-5} \mathrm{M}, 5.04 \times 10^{-5} \mathrm{M}\right]\right)$ and $2.08 \times 10^{-2} \mathrm{M}(95 \% \mathrm{CI}$ $\left[3.76 \times 10^{-3} \mathrm{M}, 4.45 \times 10^{-1} \mathrm{M}\right]$ ), respectively (Table 2, Fig. 3).

\section{DISCUSSION}

Dexmedetomidine is a unique drug that regulates the release of neurotransmitters with highly selective $\alpha_{2}$ AR agonism. The $\alpha \mathrm{AR}$ is located at both presynaptic and postsynaptic sites [16], but clinical interest in dexmedetomidine is focused on the presynaptic $\alpha_{2} \mathrm{AR}$, which controls the release of adenosine triphosphate (ATP) and norepinephrine by negative feedback [17]. The effects of dexmedetomidine via $\alpha_{2}$ AR are mediated by a second messenger system or ion channel through guanine-nucleotide regulatory binding protein activation [17].

Previously, the stimulation of $\alpha_{2}$ AR was shown to cause increases in the contractile force of the myometrium via the influx of extracellular $\mathrm{Ca}^{2+}$ through the $\mathrm{G}$ protein signal transduction pathway. Kitazawa et al. [18] reported that clonidine increased the contractile force of porcine myometrium by increasing intracellular $\mathrm{Ca}^{2+}$ without changing 3,5-cyclic adenosine monophosphate (cAMP) levels. However, there is a possibility that $\alpha_{2}$ stimulation by dexmedetomidine may increase uterine contractility by reducing cAMP formation by inhibiting adenylate cyclase [17]. In contrast, there is also a possibility that dexmedetomidine-induced $\alpha_{2}$ stimulation may decrease uterine contractility by reducing the ATP, norepinephrine, and intracellular conductance of calcium by negative feedback $[17,19]$. Thus, we aimed to evaluate the effects of dexmedetomidine on the contractility of rat myometrium.

In the current study, we first conducted a pilot study to investigate differences in the contractile profile of the myometrium according to dexmedetomidine concentrations and determine the concentrations for the probit analysis, in which the concentration-response of dexmedetomidine on pregnant myometrial strips was evaluated. The results

Table 1. Effects of Dexmedetomidine on Active Tension and the Number of Contractions in the Uterine Smooth Muscle of Pregnant Rats

\begin{tabular}{|c|c|c|c|c|c|c|}
\hline Concentration (M) & Active tension (g) & $\begin{array}{l}\text { Inhibition (\%) of } \\
\text { active tension }\end{array}$ & $P$ value & $\begin{array}{c}\text { Number of } \\
\text { contractions (n) }\end{array}$ & $\begin{array}{l}\text { Inhibition (\%) of number of } \\
\text { contractions }\end{array}$ & $P$ value \\
\hline Control & $3.74 \pm 0.22$ & - & - & $33.70 \pm 2.50$ & - & - \\
\hline $1.0 \times 10^{-4}$ & $3.45 \pm 0.14$ & $7.36 \pm 6.65$ & 0.003 & $28.30 \pm 2.31$ & $15.68 \pm 8.51$ & $<0.001$ \\
\hline $3.0 \times 10^{-4}$ & $3.10 \pm 0.08$ & $16.75 \pm 6.15$ & $<0.001$ & $22.70 \pm 1.83$ & $32.25 \pm 8.47$ & $<0.001$ \\
\hline $6.0 \times 10^{-4}$ & $2.85 \pm 0.27$ & $23.38 \pm 11.26$ & $<0.001$ & $21.80 \pm 1.87$ & $34.91 \pm 8.16$ & $<0.001$ \\
\hline $9.0 \times 10^{-4}$ & $1.16 \pm 0.18$ & $68.89 \pm 4.07$ & $<0.001$ & $14.30 \pm 1.64$ & $57.47 \pm 5.47$ & $<0.001$ \\
\hline $1.2 \times 10^{-3}$ & $0.89 \pm 0.29$ & $75.97 \pm 7.80$ & $<0.001$ & $3.90 \pm 1.20$ & $88.39 \pm 3.74$ & $<0.001$ \\
\hline
\end{tabular}

The data are expressed as mean \pm SD. $P$ values are compared to the control, $n=8$.

Table 2. Estimated Effective Concentrations (M) of Dexmedetomidine to Inhibit Active Tension and the Number of Contractions in the Uterine Smooth Muscle of Pregnant Rats

\begin{tabular}{|c|c|c|c|c|c|}
\hline $\begin{array}{l}\text { Myometrial } \\
\text { contractions }\end{array}$ & $\mathrm{EC}_{5}$ & $\mathrm{EC}_{25}$ & $\mathrm{EC}_{50}$ & $\mathrm{EC}_{75}$ & $\mathrm{EC}_{95}$ \\
\hline \multirow{2}{*}{$\begin{array}{l}\text { Active } \\
\text { tension (g) }\end{array}$} & $4.63 \times 10^{-8}$ & $2.81 \times 10^{-6}$ & $4.88 \times 10^{-5}$ & $8.49 \times 10^{-4}$ & $5.16 \times 10^{-2}$ \\
\hline & $\left(1.28 \times 10^{-9}, 2.63 \times 10^{-7}\right)$ & $\left(6.65 \times 10^{-7}, 6.59 \times 10^{-6}\right)$ & $\left(2.29 \times 10^{-5}, 1.39 \times 10^{-4}\right)$ & $\left(2.54 \times 10^{-4}, 9.06 \times 10^{-3}\right)$ & $\left(5.67 \times 10^{-3}, 5.28 \times 10^{0}\right)$ \\
\hline \multirow{2}{*}{$\begin{array}{l}\text { Number of } \\
\text { contractions } \\
\text { (n) }\end{array}$} & $3.12 \times 10^{-8}$ & $1.63 \times 10^{-6}$ & $2.55 \times 10^{-5}$ & $3.99 \times 10^{-4}$ & $2.08 \times 10^{-2}$ \\
\hline & $\left(2.16 \times 10^{-9}, 1.40 \times 10^{-7}\right)$ & $\left(5.08 \times 10^{-7}, 3.42 \times 10^{-6}\right)$ & $\left(1.41 \times 10^{-5}, 5.04 \times 10^{-5}\right)$ & $\left(1.62 \times 10^{-4}, 1.80 \times 10^{-3}\right)$ & $\left(3.76 \times 10^{-3}, 4.45 \times 10^{-1}\right)$ \\
\hline
\end{tabular}

The data are expressed as estimated value (95\% confidence interval). EC: effective concentration of $\%$ inhibition. $n=8$. 


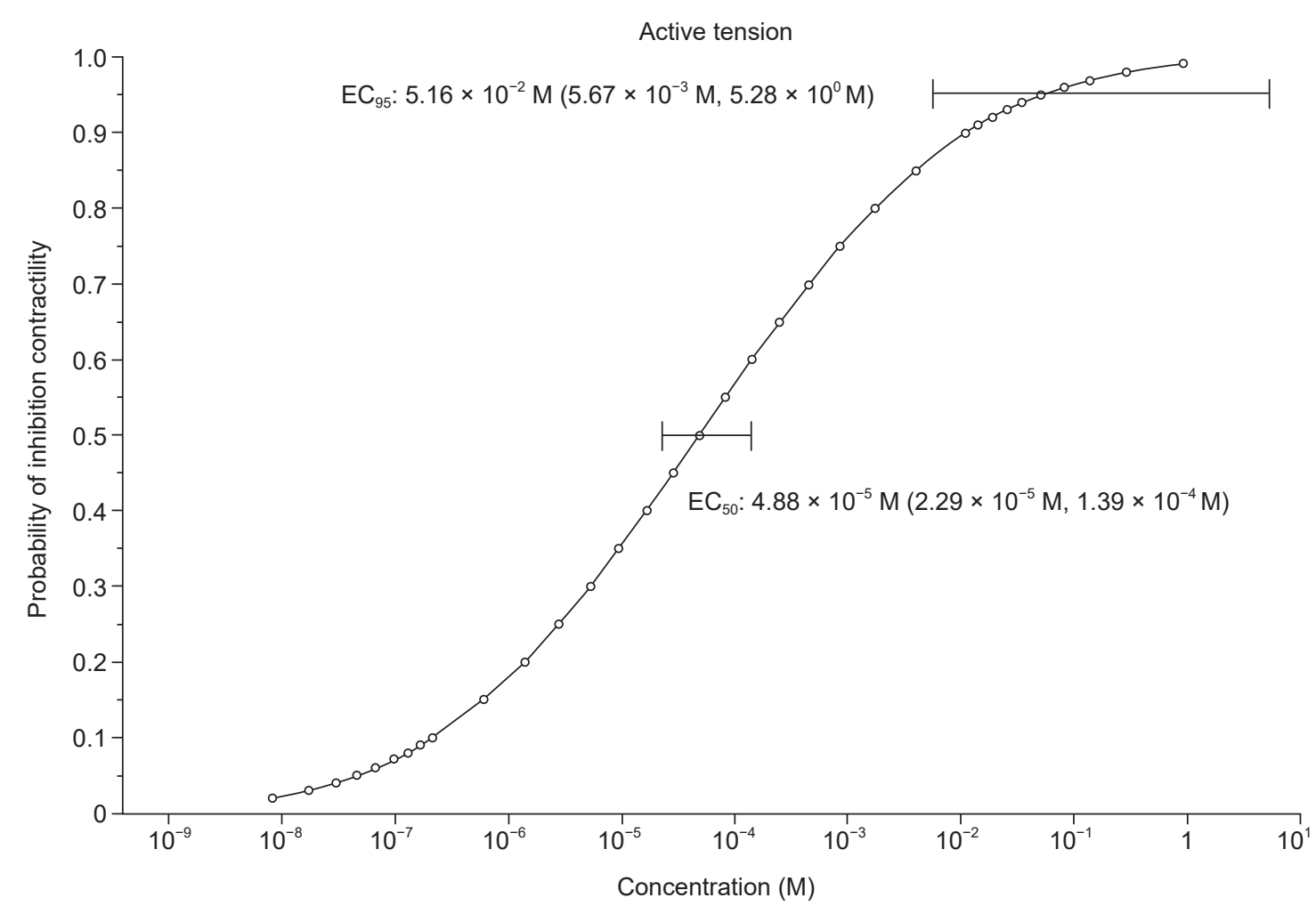

Fig. 2. Probability of inhibiting active tension of the myometrium of a pregnant rat according to the concentration of dexmedetomidine (M). The horizontal bars represent the concentration of dexmedetomidine calculated to inhibit the active tension of myometrial stirps with $50 \%$ and $95 \%$ probabilities $\left(\mathrm{EC}_{50}\right.$ and $\mathrm{EC}_{95}$ ), respectively, and a 95\% confidence interval. EC: effective concentration.

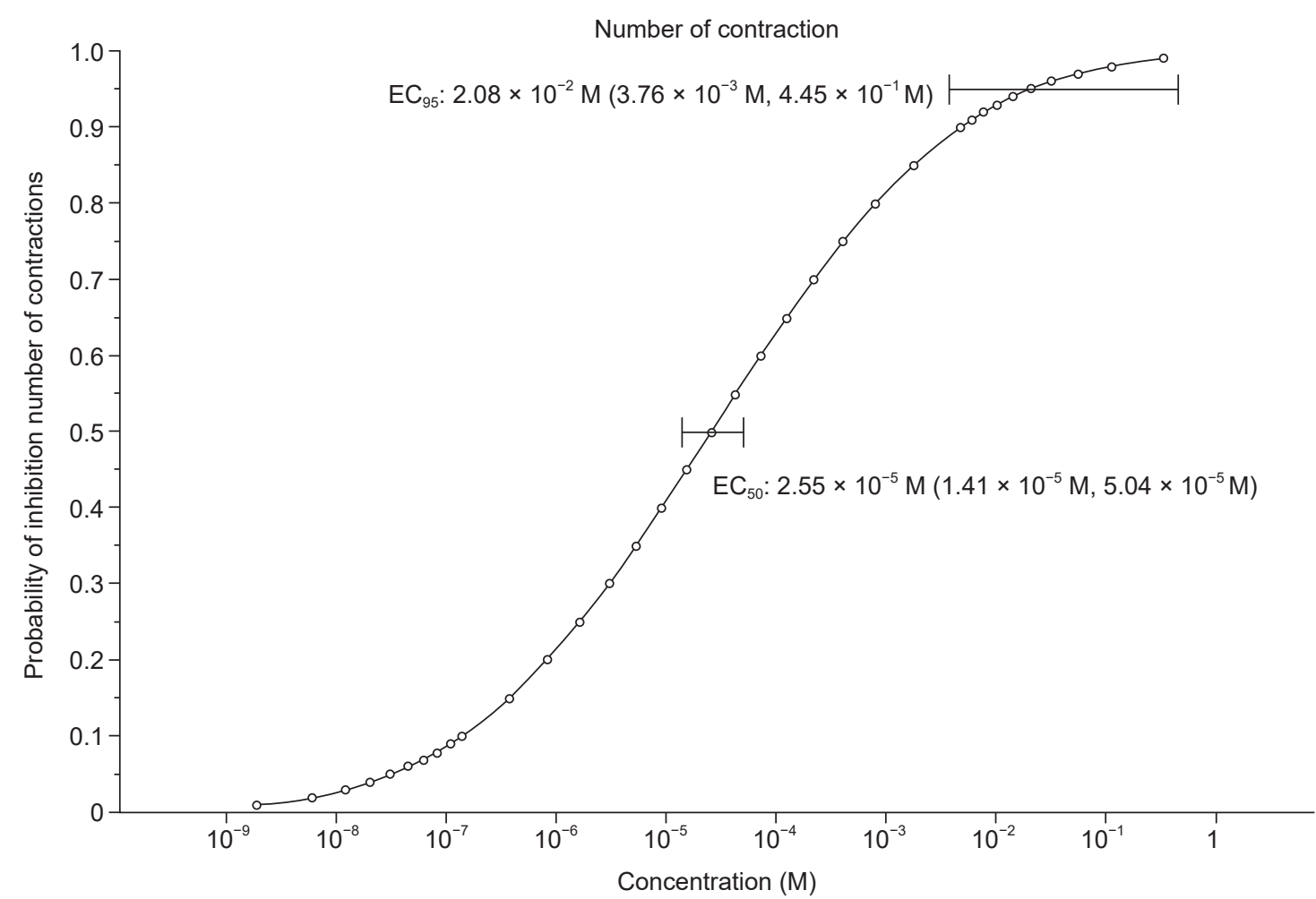

Fig. 3. Probability of inhibiting the number of myometrial contractions of a pregnant rat according to the concentration of dexmedetomidine (M). The horizontal bars represent the concentration of dexmedetomidine calculated to inhibit the number of myometrial strip contractions with $50 \%$ and $95 \%$ probabilities $\left(\mathrm{EC}_{50}\right.$ and $\mathrm{EC}_{95}$ ), respectively, and a 95\% confidence interval. EC: effective concentration. 
of the pilot study showed that the contractile profile of myometrium induced by oxytocin did not change significantly at dexmedetomidine concentrations from $10^{-6}$ to $10^{-5} \mathrm{M}$. A significant decrease was seen in active tension at $10^{-3} \mathrm{M}$ and the number of contractions at $10^{-4} \mathrm{M}$. Interestingly, a complete loss of contractions was found at $10^{-2} \mathrm{M}$. These results suggest that the $\alpha_{2}$ AR of the myometrium may display biphasic effects according to the concentration of dexmedetomidine.

According to previous studies, dexmedetomidine increased the contractility of rat myometrium at concentrations of $10^{-9} \mathrm{M}$ to $10^{-5} \mathrm{M}$ [7], and in a human myometrial strip at clinical plasma concentrations of $10^{-9} \mathrm{~g} / \mathrm{ml}$, which were calculated as $2.53 \times 10^{-3} \mathrm{M}$ in vitro [8]. Our results, which showed no significant changes in contractions at concentrations of $10^{-6}$ to $10^{-4} \mathrm{M}$, were inconsistent with the results of the previous studies. Previous studies differed from the current study in that they did not use oxytocin to stimulate the myometrium. Myometrial contractions are regulated by depolarization triggered by intracellular $\mathrm{Ca}^{2+}$ influx and calcium plays a key role in this mechanism [20]. Ocal et al. [9] reported that dexmedetomidine increased spontaneous contraction forces in a dose-dependent manner, but there was no change in late-term pregnancy rats when $\mathrm{Ca}^{2+}$-free solution was used. Oxytocin increases intracellular $\mathrm{Ca}^{2+}$ influx, which is a major mechanism of uterine contractions [20]. After labor, increased oxytocin stimulates uterine contractions, and we used oxytocin to create a similar biological environment [21]. Without oxytocin, the baseline contractility is decreased compared to when oxytocin is used, and this could be the reason for the discrepant results. Moreover, we evaluated changes in uterine contractility at higher concentrations of dexmedetomidine. The maximal concentrations of dexmedetomidine in previous studies were $10^{-5} \mathrm{M}$ [7] and $10^{-4} \mathrm{M}$ [9]. However, we found a significant decrease in active tension at $10^{-3} \mathrm{M}$ dexmedetomidine. Specifically, both the contractile force and the number of contractions disappeared at $10^{-2} \mathrm{M}$ dexmedetomidine. These results suggest that an occupation of the $\alpha$ AR of the myometrium above a certain level may relax the uterus.

Several hypotheses could explain how dexmedetomidine decreases myometrial contractility. First, the excessive stimulation of $\alpha_{2}$ AR may produce uterine relaxation by inhibiting $\alpha_{1}$ ARs. Kyozuka et al. [22] found that postsynaptic $\alpha_{2}$ AR may exist on the plasma membrane of rat myometrial smooth muscles and has no contractile function. However, they suggested that occupancy by a selective $\alpha_{2}$ agonist could competitively interact by occupying sites of the $\alpha_{1}$ AR with contractile functions. Second, dexmedetomidine may produce uterine relaxation because of its higher affinity for $\alpha_{2 \mathrm{~A}}$ and $\alpha_{2 \mathrm{C}}$ AR subtypes [23]. In pregnant rats, $\alpha_{2 \mathrm{~A}}$ and $\alpha_{2 \mathrm{C}} \mathrm{AR}$ decrease myometrial contractions, whereas $\alpha_{2 B}$ AR increases them [24]. Moreover, the expression of $\alpha_{2}$ AR subtypes is related to gestational hormones and affected by the levels of progesterone. In the non-pregnant uterus, an $\alpha_{2}$ AR agonist did not cause myometrial contractions [24]. Hajagos-Toth et al. [25] suggested the use of $\alpha_{2 \mathrm{C}}$ agonists and $\alpha_{2 \mathrm{~B}}$ antagonists with progesterone for reducing uterine contraction in the treatment of preterm labor. These results indicate that dexmedetomidine may produce uterine relaxation by the stimulation of $\alpha_{2 \mathrm{~A}}$ and $\alpha_{2 \mathrm{C}}$ AR subtypes.

In the current study, we also compare the calculated concentration from the in vitro study with the clinical concentration of dexmedetomidine for the sedation. According to clinical research on the pharmacokinetics and pharmacodynamics of dexmedetomidine, dexmedetomidine showed a significant sedative effect when the plasma concentrations were maintained between 0.2 and $0.3 \mathrm{ng} / \mathrm{ml}$ [10]. This plasma concentration was about $8.45 \times 10^{-1} \mathrm{M}$ to $1.27 \times 10^{0} \mathrm{M}$, given that the molecular weight of the dexmedetomidine is $236.74 \mathrm{~g} / \mathrm{mol}$. The effective concentrations are $5.07 \times 10^{-2} \mathrm{M}$ to $7.69 \times 10^{-2} \mathrm{M}$ in vitro because the protein binding of dexmedetomidine is $94 \%$ [10]. These concentrations are similar to the $\mathrm{EC}_{95}$ of dexmedetomidine to inhibit active tension $\left(5.16 \times 10^{-2} \mathrm{M}\right)$ and the number of myometrial contractions $\left(2.08 \times 10^{-2} \mathrm{M}\right)$ in the current study. Thus, there is a possibility that uterine contractility might be decreased when dexmedetomidine is used for sedation in pregnant women, which may cause problems after delivery. However, we cannot be sure whether those hypotheses can be applied to clinical situations because there are significant differences between species.

There were several limitations to our study. We did not evaluate the responses after the simultaneous stimulation or inhibition of adrenergic receptors. It is possible that interactions between the receptors could regulate uterine contractions. Also, there would be interactions and feedback mechanisms between a AR and other physiologic receptors. The results of the current study were not validated in humans. Thus, a well-designed clinical study is needed for the safe use of dexmedetomidine in pregnant women.

In conclusion, active tension of the myometrium did not change at concentrations of dexmedetomidine less than 
$10^{-4} \mathrm{M}$ but showed a significant decrease at concentrations higher than $10^{-3} \mathrm{M}$. The $\mathrm{EC}_{95}$ of dexmedetomidine to inhibit active tension and the number of contractions was 4.88 $\times 10^{-5} \mathrm{M}$ and $2.55 \times 10^{-5} \mathrm{M}$, respectively. The use of dexmedetomidine at clinical concentrations in pregnant women has the potential to relax uterine muscles, so further research is needed for the safe use of dexmedetomidine in the obstetrics field.

\section{ACKNOWLEDGEMENTS}

This study was supported by research fund from Chosun University Hospital, 2019.

\section{CONFLICTS OF INTEREST}

No potential conflict of interest relevant to this article was reported.

\section{AUTHOR CONTRIBUTIONS}

Conceptualization: Ki Tae Jung. Experiment conduction: Young Joon Ki, Bo Hyun Jang, Seongcheol Kim, Ki Tae Jung. Data acquisition: Dong Joon Kim, Ki Tae Jung. Formal analysis: Sang Hun Kim, Ki Tae Jung. Funding: Ki Tae Jung. Supervision: Ki Tae Jung. Writing-original draft: Dong Joon Kim, Ki Tae Jung. Writing-review \& editing: Sang Hun Kim, Ki Tae Jung.

\section{ORCID}

Dong Joon Kim, https://orcid.org/0000-0002-3072-4734

Young Joon Ki, https://orcid.org/0000-0001-6203-3690

Bo Hyun Jang, https://orcid.org/0000-0003-3123-9033

Seongcheol Kim, https://orcid.org/0000-0002-2895-3001

Sang Hun Kim, https://orcid.org/0000-0003-3869-9470

Ki Tae Jung, https://orcid.org/0000-0002-2486-9961

\section{REFERENCES}

1. Lee S. Dexmedetomidine: present and future directions. Korean J Anesthesiol 2019; 72: 323-30.

2. Nair AS, Sriprakash K. Dexmedetomidine in pregnancy: review of literature and possible use. J Obstet Anaesth Crit Care 2013; 3: 3-6.

3. Mendoza Villa JM. Dexmedetomidine as adjunct for analgesia in labor: a report of two cases. Rev Colomb Anestesiol 2012; 40:
79-81.

4. El-Arab NKE, El-Hawary SI, El-Zeftawy AE, Mohammed RM. Dexmedetomidine in preeclamptic patients undergoing caesarean section under general anesthesia. Tanta Med J 2017; 45: 220-5.

5. Mishra N, Jain A, Sharma M. Intravenous dexmedetomidine for labour analgesia in women with preeclampsia. J Evol Med Dent Sci 2016; 5: 3408-11.

6. Wang J, Han Z, Zhou H, Wang N, Ma H. Effective loading dose of dexmedetomidine to induce adequate sedation in parturients undergoing caesarean section under spinal anaesthesia. Turk J Anaesthesiol Reanim 2017; 45: 260-3.

7. Karaman S, Evren V, Firat V, Cankayali I. The effects of dexmedetomidine on spontaneous contractions of isolated gravid rat myometrium. Adv Ther 2006; 23: 238-43.

8. Sia AT, Kwek K, Yeo GS. The in vitro effects of clonidine and dexmedetomidine on human myometrium. Int J Obstet Anesth 2005; 14: 104-7.

9. Öcal I, Güneş Y, Mert T, Özcengiz D, Günay I. Dexmedetomidine modifies uterine contractions in pregnancy terms of rats. Indian J Pharmacol 2013; 45: 168-73.

10. Weerink MAS, Struys MMRF, Hannivoort LN, Barends CRM, Absalom AR, Colin P. Clinical pharmacokinetics and pharmacodynamics of dexmedetomidine. Clin Pharmacokinet 2017; 56: 893-913

11. Kim M. Study on adrenoceptors of the rat uterus. Hanyang J Med 1982; 2: 383-93.

12. Kilkenny C, Browne W, Cuthill IC, Emerson M, Altman DG; National Centre for the Replacement, Refinement and Reduction of Amimals in Research. Animal research: reporting in vivo experiments--the ARRIVE guidelines. J Cereb Blood Flow Metab 2011; 31: 991-3.

13. Agoston DV. How to translate time? The temporal aspect of human and rodent biology. Front Neurol 2017; 8: 92.

14. Chung CD, An TH, Jung KT, Lee TH. The effects of etomidate on the contraction of pregnant rat uterine smooth muscle. Korean J Anesthesiol 2009; 57: 84-7.

15. Lee S, Hwang GB, Baik CY. The relationship of the estimates of effective concentration calculated by logit, probit, and sigmoid Emax. Korean J Anesthesiol 2002; 43: 345-7.

16. Drew GM, Whiting SB. Evidence for two distinct types of postsynaptic alpha-adrenoceptor in vascular smooth muscle in vivo. Br J Pharmacol 1979; 67: 207-15.

17. Gertler R, Brown HC, Mitchell DH, Silvius EN. Dexmedetomidine: a novel sedative-analgesic agent. Proc (Bayl Univ Med Cent) 2001; 14: 13-21.

18. Kitazawa T, Maezono Y, Taneike T. The mechanisms of al 
pha(2)-adrenoceptor agonist-induced contraction in longitudinal muscle of the porcine uterus. Eur J Pharmacol 2000; 390: 185-95.

19. Berg G, Andersson RG, Ryden G. Alpha-adrenergic receptors in human myometrium during pregnancy. Am J Obstet Gynecol 1986; 154: 601-6.

20. Arrowsmith S, Wray S. Oxytocin: its mechanism of action and receptor signalling in the myometrium. J Neuroendocrinol 2014; 26: 356-69.

21. Kim DJ, Hwang MH, An TH, Jung KT. The relaxant effect of nicardipine on the isolated uterine smooth muscle of the pregnant rat. Anesth Pain Med 2019; 14: 429-33.

22. Kyozuka M, Crankshaw DJ, Crankshaw J, Berezin I, Kwan CY, Daniel EE. Alpha-2 adrenoceptors on nerves and muscles of rat uterus. J Pharmacol Exp Ther 1988; 244: 1128-38.

23. Fairbanks CA, Stone LS, Wilcox GL. Pharmacological profiles of alpha 2 adrenergic receptor agonists identified using genetically altered mice and isobolographic analysis. Pharmacol Ther 2009; 123: 224-38.

24. Gáspár R, Gál A, Gálik M, Ducza E, Minorics R, Kolarovszki-Sipiczki Z, et al. Different roles of alpha2-adrenoceptor subtypes in non-pregnant and late-pregnant uterine contractility in vitro in the rat. Neurochem Int 2007; 51: 311-8.

25. Hajagos-Tóth J, Bóta J, Ducza E, Samavati R, Borsodi A, Benyhe $\mathrm{S}$, et al. The effects of progesterone on the alpha2-adrenergic receptor subtypes in late-pregnant uterine contractions in vitro. Reprod Biol Endocrinol 2016; 14: 33. 